\title{
Clogging vs. fouling in immersed membrane bioreactors
}

\author{
Buzatu, P. ${ }^{1}$, Qiblawey, H. ${ }^{2}$, Odai, A. ${ }^{1}$, Jamaleddin, J. ${ }^{1}$, Nasser, M. ${ }^{1}$, and Judd, S.J. ${ }^{1,3^{*}}$ \\ ${ }^{1}$ Gas Processing Center, Qatar University; ${ }^{2}$ Department of Chemical Engineering, Qatar University; ${ }^{3}$ Cranfield \\ Water Science Institute, Cranfield University. *corresponding author.
}

\begin{abstract}
Whilst the fouling of MBR membrane surfaces has been very extensively explored by the academic community, there is an increasingly widespread recognition by practitioners of the issue of clogging of membrane channels with sludge solids, sometimes termed "sludging". The study undertaken has quantified this phenomenon using a bespoke test cell allowing a flat sheet membrane channel to be viewed directly during operation and the accumulated solids determined by digital image processing. Sludging behaviour has then been correlated both with the sludge properties, from sludge samples taken from both an industrial and municipal MBR, and the permeability decline rate data.
\end{abstract}

The work has revealed the expected trends in fouling propensity, as quantified by the exponent $n$ of the $\Delta p / \Delta t=m \cdot \exp (n J)$ correlation from classical flux-step tests. With zero membrane aeration the industrial samples exhibited sludging, the filling of the complete thickness of the membrane channel with sludge solids, whereas for municipal sludge the solids formed a cake layer which did not fill the channel. In the absence of sludging the permeability decline followed the expected pattern of increasing at the elevated soluble COD and capillary suction time values of the industrial sludge, compared with municipal sludge at the same solids concentration range (8-12 g. $\left.\mathrm{L}^{-1}\right)$. However, there was no evident correlation between fouling (permeability decline without sludging) and sludging: incipient sludging did not appear to influence permeability, though can be assumed to negatively impact on long-term operation, or relate to the sCOD concentration. Sludging instead appeared to depend on the sludge physical properties, and primarily the viscosity: sludge samples at high viscosities were found to exhibit a different air-scour pattern to that at normal MLSS concentrations.

Outcomes suggests that sludging is caused by rheological conditions promoting bubble coalescence and bubble stream constriction, reducing the exposure of the membrane surface to scouring air.

Keywords Membrane bioreactors; sludge; clogging; sludging; fouling; rheology

\section{Introduction}

Membrane bioreactor (MBR) technology is known to be constrained by the tendency for the membrane permeability to decrease during the filtration cycle. This demands periodic physical and chemical cleaning, which then increases operating costs due to the downtime incurred. The reduction in the operating flux also increases the membrane area demanded, impacting on capital costs.

Permeability reduction has almost exclusively been attributed to membrane surface fouling by the scientific community, with regular reviews on fouling characterisation and mitigation published in learned journals (Le Clech et al, 2006; Kraume and Drews, 2010; Lin et al, 2014), including three in 2017 alone (Aslam et al, 2017; Krzeminski et al, 2017; Meng et al, 2017). However, within the practitioner community the impact of membrane channel clogging or "sludging" (or, sometimes, "localised dewatering", Stone and Livingston, 2008), the filling of the membrane interstices with sludge solids, is widely recognised as being as problematic as fouling (Stone and Livingston, 2008; Mason et al, 2010, Gabarrón et al, 2013, 2014; The MBR Site, 2015; Wang et al, 2018) for both hollow fibre (HF) and flat sheet (FS) membranes. Whilst fouling is generally effectively ameliorated through cleaning physically (Aslam et al, 2017) and chemically (Wang et al, 2014), in practice these strategies have little or no impact on clogging. Clogging - including "ragging" or braiding of short filaments to form long rag-like particles (Stefanski et al. 2011) - usually demands manual intervention to clear out the solids (Mason et al, 2010, Stefanski et al. 2011; Gabarrón et al, 2013). Such intervention is time- 
consuming, labour-intensive and potentially damaging to the membranes, all factors significantly impacting on costs to a greater extent than adjustment of the chemical cleaning protocol to mitigate surface fouling.

It has been assumed by practitioners that problems associated with clogging are only effectively ameliorated through both:

a) fine screening of the feed to remove the inlet gross solids (Frechen et al. 2008; Impero, 2015), incurring additional costs associated with screenings management, and

b) appropriately limiting the MLSS (mixed liquor suspended solids) concentration in the membrane tank (Zsirai et al, 2014).

However, there has been very limited research on clogging/sludging, to substantiate these rules of thumb. Despite its practical significance, only a few isolated studies (Buzatu at al, 2011, Zsirai et al, 2014) have sought to quantify sludging gravimetrically. Specifically, the key MLSS characteristics to which sludging may be attributed have not been identified, such that the efficacy of any remedial measures taken to address it cannot be established. This is in stark contrast with corresponding research into membrane surface fouling, apparently comprising $25-30 \%$ of all published research into MBR technology in the past 15 years (Judd, 2017).

This paper aims to provide further insight into sludging phenomena in iMBRs through experimental study of MLSS samples extracted from full-scale operating MBRs. The work, only the third study quantifying sludging in MBRs, made use of a bespoke bench-scale test cell which allowed the filterability of MLSS samples to be directly measured along with the sludging rate, through accelerated testing. The filterability measurements were supplemented by measurement of commonly recorded sludge bulk characteristics, namely the capillary suction time (CST) and sludge volume index (SVI), along with rheological characterisation.

\section{Materials and methods}

\subsection{Plant description and monitoring}

The iMBR test cell (Fig. 1) consisted of a single A4-sized, 6 mm-thick flat sheet (FS) membrane panel (Kubota Membranes Europe, London) housed in a $~ 500 \mathrm{~mm}$-tall rectangular acrylic tank $(130 \mathrm{~mm}$ width, $245 \mathrm{~mm}$ length). The membrane was placed between the tank wall and an acrylic baffle spaced at a distance of $6 \mathrm{~mm}$ from the membrane surface, this channel thickness being equal on both sides of the membrane panel to avoid imbalance of flows. The acrylic construction allowed the membrane surface to be directly viewed to observe sludging in the form of agglomerated solids within the channel. The non-visible side of the membrane was sealed, such that flow through the membrane was limited to the viewable side. A fine-bubble aerator was placed in the process tank to mix the MLSS flocs and provide dissolved oxygen to the biomass.

The permeate was removed under suction using a peristaltic pump able to achieve a flow of up to $500 \mathrm{~mL} / \mathrm{min}$. It was then fed to a de-aerator, a simple open $2 \mathrm{~L}$ cylindrical tank, and the overflow from this tank allowed to flow through a digital flowmeter. The permeate line was also fitted with a digital pressure sensor operating within the range of -0.6 to +0.6 bar.

\subsection{Physical and rheological characterisation}

Sludge samples were collected on alternate weeks from the membrane tanks of two nearby full-scale MBR installations, one being a $32,000 \mathrm{~m}^{3} /$ day capacity municipal wastewater treatment plant (WwTP) and the other a $50 \mathrm{~m}^{3} /$ day plant treating petroleum industrial effluent. All samples were physically and chemically characterised immediately after being brought to the University laboratories. The physical characteristics of the sludge were assessed with reference to the MLSS, particle size (using a Mastersizer 2000, Malvern Instruments Ltd., UK), capillary suction time (CST), and sludge volume index (SVI), all according to standard methods (APHA, 2012). Chemical characterisation was limited to the filtered (or soluble) $\mathrm{COD}$, conductivity, $\mathrm{NaCl}$ concentration and $\mathrm{pH}$. 


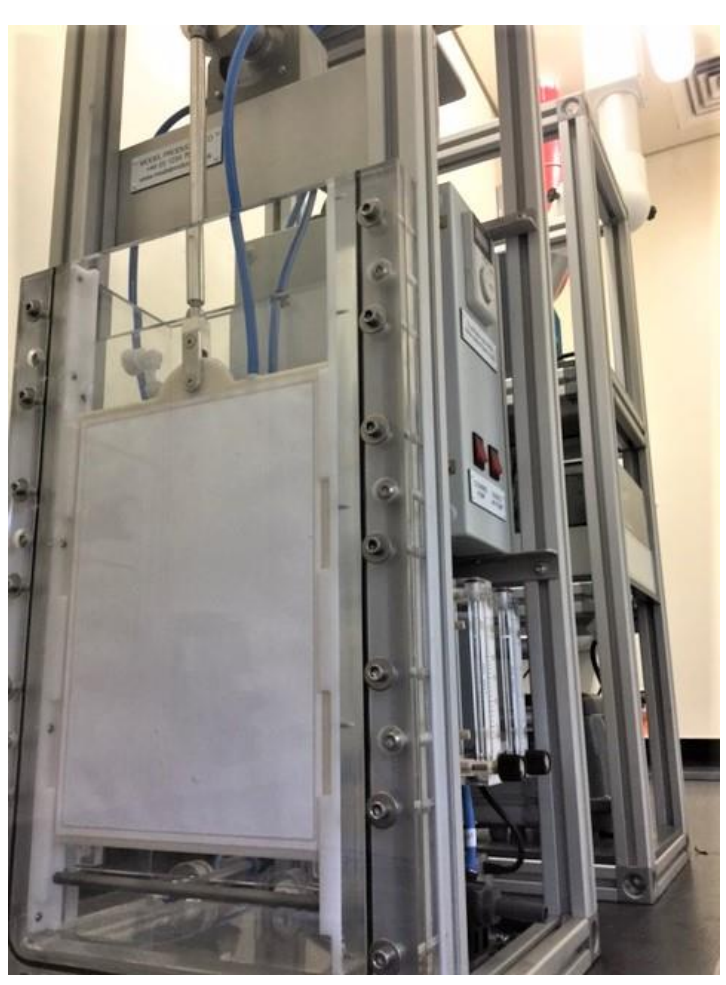

(a)

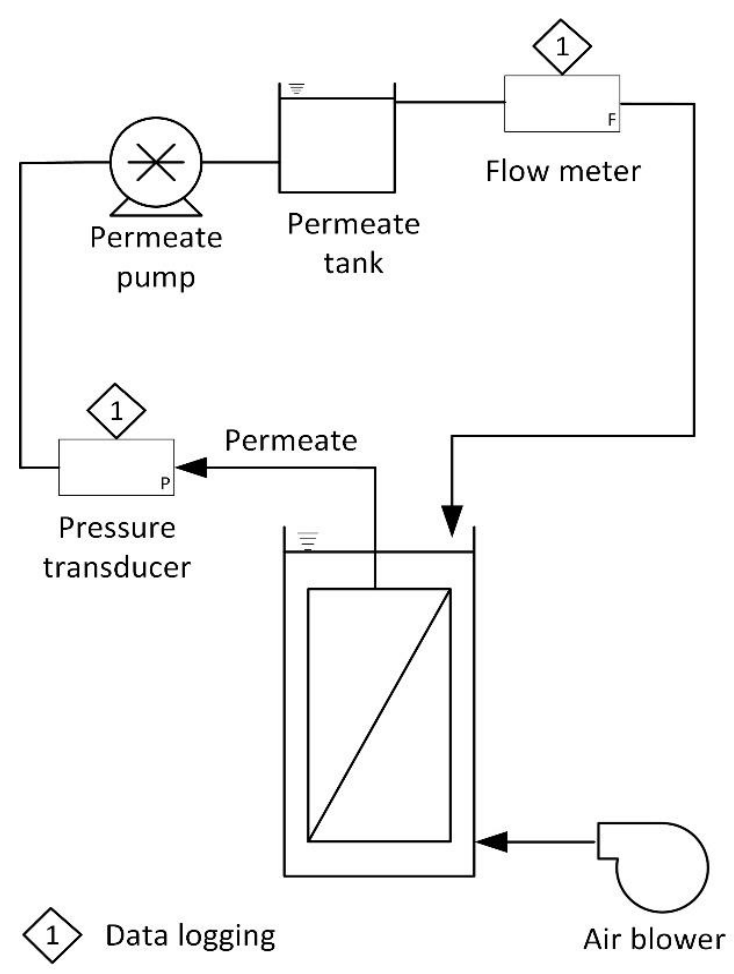

(b)

Figure 1: The MBR test cell, (a) membrane and channel, and (b) schematic.

Rheological characterisation was based on the determination the evolution of viscosity over time using a controlled stress and strain rheometer (Anton Paar Model MCR 302, Austria) with a cup and bob configuration (DIN coaxial cylinder). The temperature was set at $20^{\circ} \mathrm{C}$ and a new sample (approximately $20 \mathrm{~mL}$ volume) used for each applied shear rate. Measurements were performed under constant shear-rate until steady state was reached (after between 30 and 60 minutes, the equilibration time decreasing with increasing shear rate). The equilibrium value was recorded for shear rates between 20 and $120 \mathrm{~s}^{-1}$.

\subsection{Fouling and sludging propensity}

The fouling and sludging characteristics of the sludge samples were determined through a combination of:

a) a classical flux step test (Le Clech et al, 2003; van den Brink, 2011; Diez et al, 2014; Ranieri et al, 2016), based on one-hour steps and an initial flux $(J)$ of 5 or $10 \mathrm{~L} \mathrm{~m}^{-2} \mathrm{~h}^{-1}(\mathrm{LMH})$;

b) extended (2-4 h) "fouling rate" (pressure incline rate, $\mathrm{dP} / \mathrm{dt}$ ) measurement at a single flux, the flux measurement being selected according to the outcomes of (a);

c) sludging rate measurement, recorded simultaneously with (b) above.

Tests were conducted with recirculated permeate to conserve the total solids, and ended when the transmembrane pressure (TMP, $p$ ) exceeded 190 mbar for Campaigns 1-2 (Table 1), and 590 mbar for Campaign 3. Original trials with the industrial sludge samples were conducted using coarse-bubble aeration at an air flow of $2 \mathrm{~L} \cdot \mathrm{min}^{-1}$, ensuring a velocity of approximately $0.011 \mathrm{~m} \cdot \mathrm{s}^{-1}$ based on equal distribution of the air either side of the membrane panel. This value was chosen so as to replicate those used elsewhere (Böhm and Kraume, 2015; Yang et al, 2017), as well as being comparable to those encountered in full-scale systems (Verrecht et al, 2008). Subsequent tests were conducted without membrane aeration, the crossflow within the membrane channel being provided by the downward 
motion of the sludge from the air-lifting of the sludge in the bioreactor compartment. The membrane channel in this instance acted as a downcomer. This reduced the effective crossflow to 0.001-0.003 m. $\mathrm{s}^{-}$ ${ }^{1}$, increasing the fouling and sludging propensity accordingly.

Table 1.Summary of campaigns

\begin{tabular}{l|llll}
\hline Campaign & Source & MLSS, $\boldsymbol{g} . \boldsymbol{L}^{-\boldsymbol{I}}$ & $\boldsymbol{U}_{\boldsymbol{a}}, \boldsymbol{m . s}^{-\boldsymbol{I}}$ & No. tests \\
\hline 1 & Ind. & $10-12$ & 0.011 & 16 \\
2 & Ind., Mun. & $8-12$ & 0 & 28 \\
3 & Ind., Mun. & $16-22$ & $0-0.055$ & 19 \\
\hline
\end{tabular}

$U_{a}=$ Air flow rate/cross-sectional area

Pressure-response studies took place at single flux values selected as being at or close to the sustainable (or "critical") flux value indicated by the flux step experiments. The tests were conducted for repeated periods of one hour, the reactor sludge being discharged slowly after each period to avoid disturbing any sludged solids in the channel. Images of the membrane were captured through the transparent wall and processed using an in-house Matlab program to determine the percentage of the membrane surface occluded by sludge solids. Surface coverage rates, expressed in $\%$ of coverage/h, were then calculated from the percentage occluded divided by the time passed from the start of the test. The sludge was then returned to the reactor and the test continued for another hour until the threshold pressure was reached.

The recorded change in pressure per unit time, $\Delta p / \Delta t=\left(p_{\text {fin }}-p_{\text {init }}\right) /\left(t_{\text {fin }}-t_{\text {init }}\right)$, was converted to the permeability decline rate $\Delta K / \Delta t$ in units of $\mathrm{mLMH}$ per bar per h, i.e. $\mathrm{mL} \cdot \mathrm{m}^{-2} \cdot$ bar $^{-1} \cdot \mathrm{h}^{-2}$ (equivalent to S.I units of $\left.1.30 \times 10^{18} \mathrm{~kg} \cdot \mathrm{s}^{-5}\right) . \Delta K / \Delta t$ was then correlated with the recorded sludge characteristics.

The membrane was removed from the tank between each successive test, mechanically cleaned of any attached sludge solids and soaked overnight in $500 \mathrm{mg} \mathrm{L}^{-1}$ hypochlorite to remove foulants and restore the original permeability.

\section{Results and discussion}

\subsection{Rheological and bulk sludge characterisation}

The trend in apparent viscosity $\mu_{a}$ with shear rate $\gamma$ did not significantly vary between samples, comprising an exponential decline between 20 and $120 \mathrm{~s}^{-1}$ (Fig. 2) with a neo-constant value thereafter. The $\mathrm{R}^{2}$ value for the exponent value $b$ (where $\mu_{a, \gamma=20-120 s^{-1}}=a \gamma^{-b}$ ) varied from 0.92 to 1.00 across all of the samples tested, with the greater data scatter demonstrated for the municipal sludge samples.

Examination of the data for the two sludges at the different concentrations tested indicated the $b$ vales to vary little across the different samples tested for sludges of the same origin within the same concentration range of 8-12 g.L. $\mathrm{L}^{-1}$. However, the municipal sludge samples were found to be generally less viscous but more shear-thinning than the industrial ones. The mean absolute $\mu_{a}$ value, taken at a shear rate of $120 \mathrm{~s}^{-1}$ so as to roughly comply with the shear prevailing in an immersed MBR (Yang et al, 2017), was found to be $2.1 \pm 20 \%$ for the municipal sludge samples and $11.6 \pm 5 \%$ for the industrial ones. The corresponding $b$ values were $-1.19 \pm 15 \%$ and $-0.69 \pm 15 \%$ respectively. Neither the slope nor the $\mu_{a, \gamma=120 s^{-1}}$ values were found to correlate with the solids concentration within the MLSS range for each sludge type studied for this campaign.

The classical sludge bulk quality parameters of CST and SVI also indicated similar ranges of values for sludges of the same origin. The CST of the municipal sludge ranged from 4 to $5.5 \mathrm{~s}, 4.7 \mathrm{~s}$ on average, compared to 16 to $30 \mathrm{~s}$ and $23.2 \mathrm{~s}$ on average for the industrial sludge. The industrial sludge was not settleable $(\mathrm{SVI}=100 \mathrm{~mL}$ ), whereas the SVI of the sampled municipal sludge was in the $76-83 \mathrm{~mL}$ range. This reflected the differing floc size ranges of the two sludges, the municipal sludge being substantially over $200 \mu \mathrm{m}$ in floc size compared with a $\mathrm{d}_{50}$ value of $17 \mu \mathrm{m}$ on average for the industrial sludge samples. 


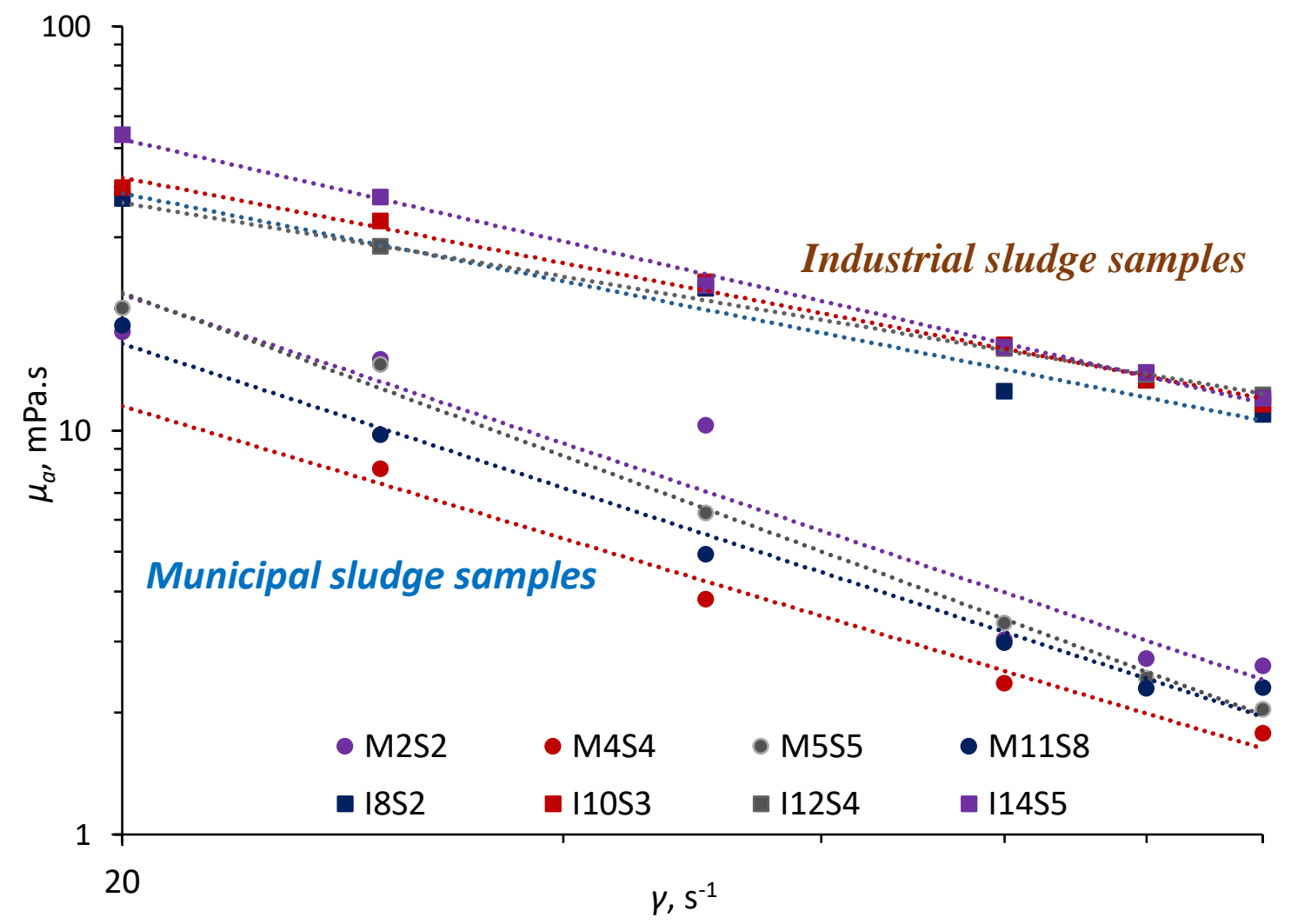

Figure 2: $\quad$ Example apparent viscosity $\mu_{a}$ vs. shear rate $\gamma$ trends for municipal (prefix "M") and industrial (prefix "I") sludge samples (four samples each, 8-12 g.L $\mathrm{L}^{-1}$ MLSS), $\gamma=20-120 \mathrm{~s}^{-1}$, with accompanying linear regression data.

\subsection{TMP response studies}

\subsubsection{Flux step}

The flux step experiments indicated the fouling rate trends (Fig. 3) to follow the expected pseudoexponential relationship $\Delta p / \Delta t=m \cdot \exp (n J)$ for those tests where there was a sufficient number of data points to provide a trend, but with little evidence of an inflection in the so-called "critical flux" region (Le Clech et al, 2003). Both the data and the slope values were more highly scattered for the industrial sludge samples. For Campaign 1 (aerated sludge) the $\mathrm{R}^{2}$ values for the industrial sludge samples ranged from 0.86 to $0.99,0.94$ on average, compared with $0.96-1.00$ and 0.99 on average for the municipal sludge samples. The corresponding ranges of slope values $n$ were $0.14-0.29$ for the industrial sludge, 0.20 on average, compared with $0.058-0.089$ and 0.077 on average for the municipal sludge.

Fouling rate $(n)$ values have been reported or else can be determined from reported data for both HF (Monclus et al, 2010; Zsirai et al. 2012; Diez et al. 2014) and FS (van der Marel et al. 2009; van den Brink et al., 2011) configurations. Overall, a full-scale PVDF HF module challenged with municipal mixed liquors of 7-10 g. . ${ }^{-1}$ MLSS and operating at air scour rates of $0.25 \mathrm{Nm}^{3} \cdot \mathrm{h}^{-1} \cdot \mathrm{m}^{2}$ the determined $n$ values range from as low as 0.05 (Guglielmi et al. 2007) up to 0.23 (Monclus et al, 2010). Corresponding values for FS membranes have tended to be lower, e.g. 0.05-0.13, van der Marel et al., 2009; 0.06-0.08 van den Brink et al, 2011, due to the higher shear imparted. For FS membranes the air bubble completely fills the channel, leading to greater shear forces than for the HF configuration where the bubbles serve mainly to agitate the fibres (Cui et al, 2003; Fulton et al, 2011). In the current study, the mean $n$ value of 0.077 for the aerated municipal sludge is within the range of that reported by authors for FS membranes (van der Marel et al., 2009; van den Brink et al, 2011).

The flux step tests generally resulted in no sludging, such that the exponent value $n$, represented the fouling propensity. Correlations of $n$ with the key parameters of CST and SCOD (the latter roughly reflecting the dissolved/colloidal foulant concentration) across the complete data set indicated the 
expected increase in $n$ with both CST and SCOD (Fig. 4). For the individual data sets specific to the individual sludge origin there was no statistically significant correlation between $n$ and either CST or sCOD at either zero or $0.011 \mathrm{~m} \cdot \mathrm{s}^{-1}$ aeration, primarily because the range of values of CST and sCOD were low - particularly for the municipal sludge. However the aerated sludge samples yielded the expected consistently higher flux than the unaerated samples, the increase for municipal sludge being significantly greater than that observed for the industrial sludge. Also, the higher permeability decline rates of the industrial sludge samples may at least in part with the higher SCOD and CST levels (Reid et al, 2008).

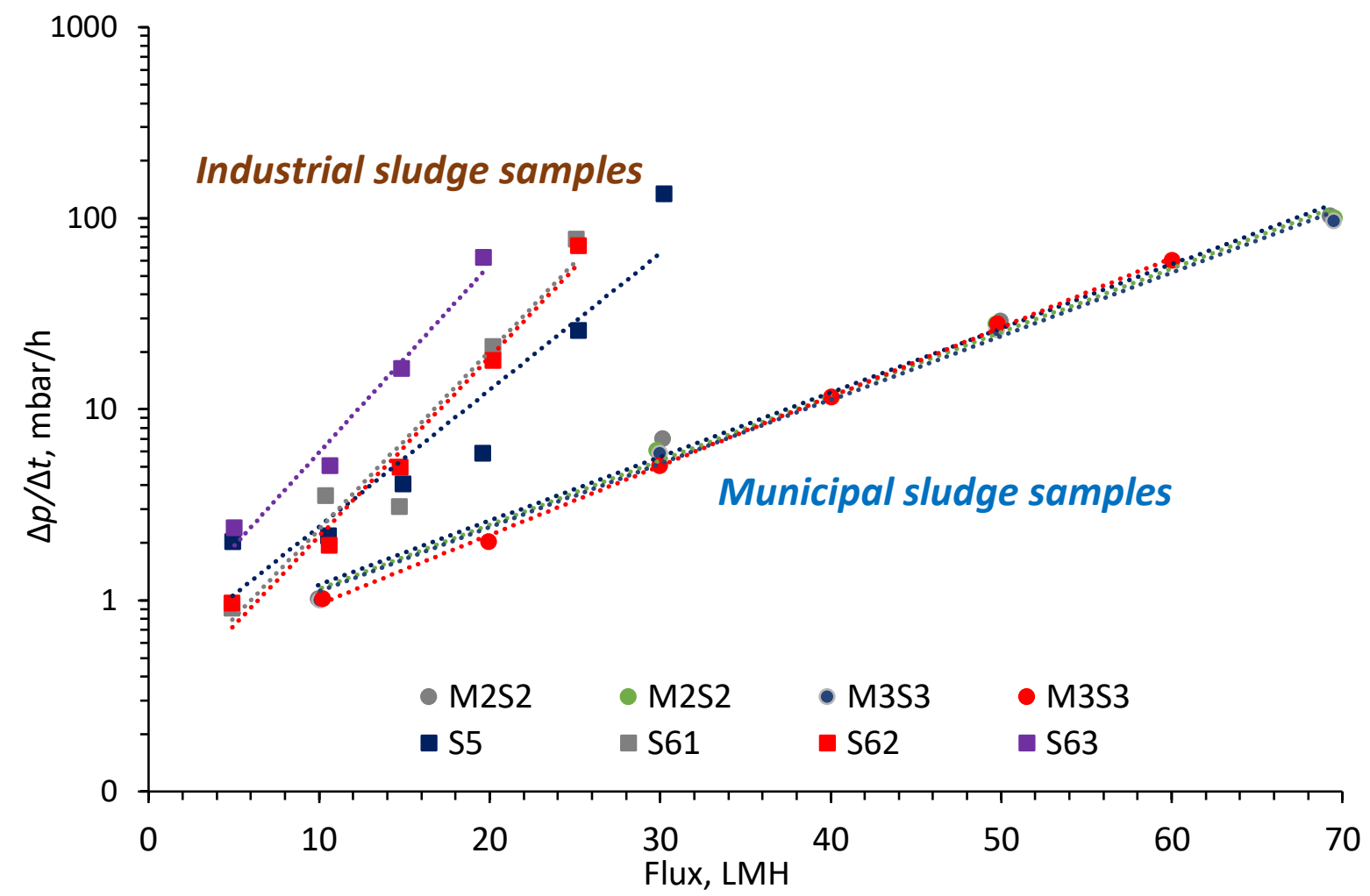

Figure 3: Example $\Delta p / \Delta t$ vs. flux trends for municipal (prefix "M") and industrial (prefix "I") sludge samples (four samples each, 8-12 g. $\mathrm{L}^{-1}$ MLSS), Campaign $1\left(\mathrm{U}=0.011 \mathrm{~m} . \mathrm{s}^{-1}\right)$, with accompanying linear regression data.

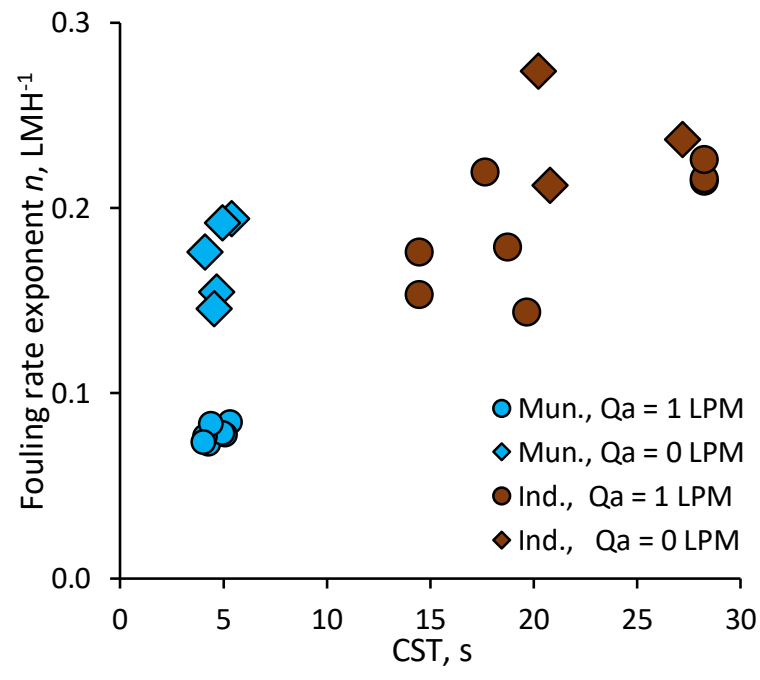

a

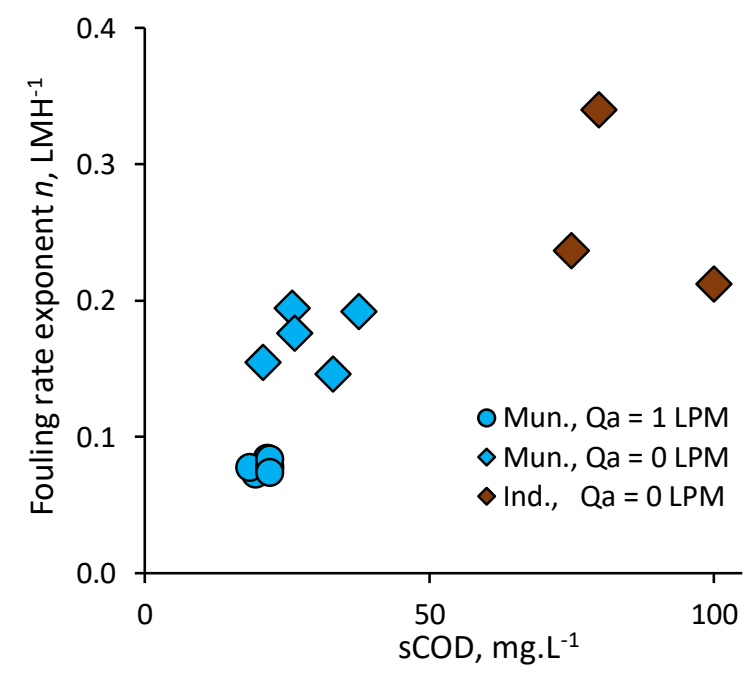

$\mathrm{b}$

Figure 4: $\quad$ Fouling propensity $n$ against (a) capillary suction time, and (b) soluble (or filtered) COD (sCOD) of the sludge samples, Campaigns 1 and 2, MLSS $=8-12$ g.L. ${ }^{-1}$. 


\subsection{Solids accumulation}

Solids accumulation (i.e. sludging) was observed only under conditions of either (a) "normal" solids concentrations (8-12 g. $\mathrm{L}^{-1}$ ) combined with zero aeration (Campaign 2), and (b) "high" solids concentration (16-22 g. $\mathrm{L}^{-1}$ ) combined with aeration at up to $0.05 \mathrm{~m} . \mathrm{s}^{-1}$ (Campaign 3). During the zero aeration conditions of Campaign 2 all but one of the 12 municipal sludge samples tested demonstrated sludging. In the case of the industrial sludge samples, for which the measured sustainable flux was lower, only five of the 15 samples exhibited sludging. Under the classical operating conditions of 8-12 g. $L^{-1}$ MLSS concentration and $0.011 \mathrm{~m} . \mathrm{s}^{-1}$ aeration employed in Campaign 1 the pressure incline was entirely associated with fouling for both sludge types.

Captured images of the membrane channel taken for the sludges from two different sources (Fig. 5) indicated the nature of solids accumulation to differ markedly between the two sludge sources. The municipal sludge samples (Fig 5a) tended to form a relatively thin cake on the membrane surface which did not fill the channel, whereas the industrial sludge samples (Fig $5 b$ ) filled part of the channel completely. Under the conditions employed, which intentionally exacerbate sludging, the rate of sludging varied from 15 to $42 \% \mathrm{~h}^{-1}$, the percentage referring to the proportion of the membrane occluded by the solids deposit.
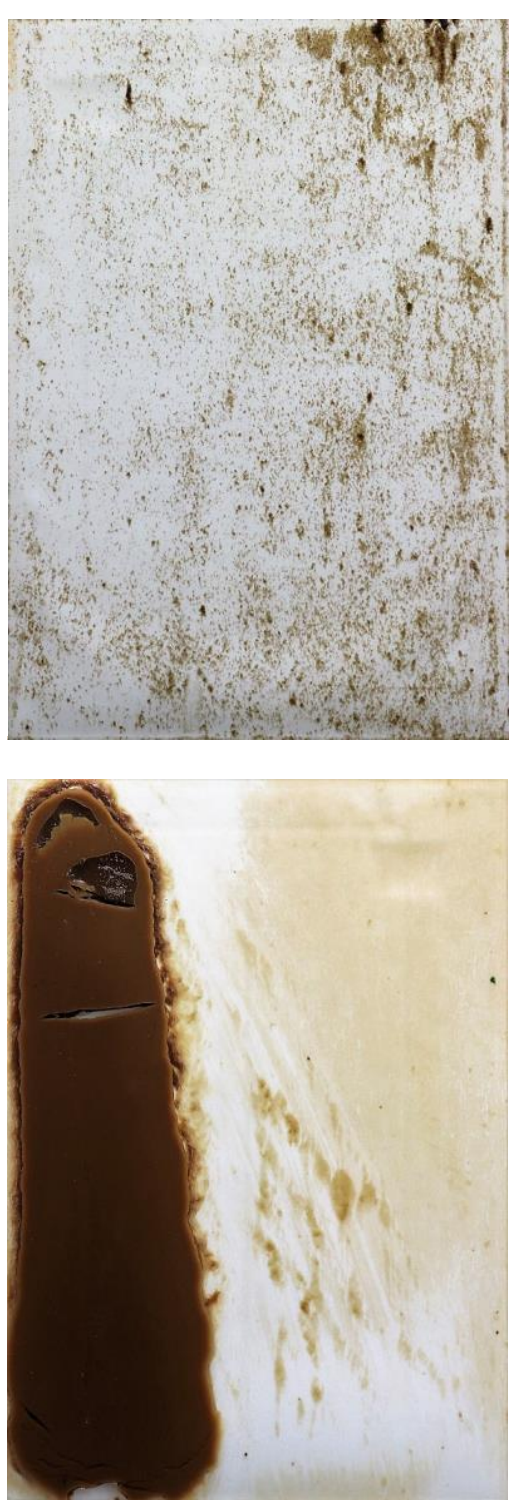
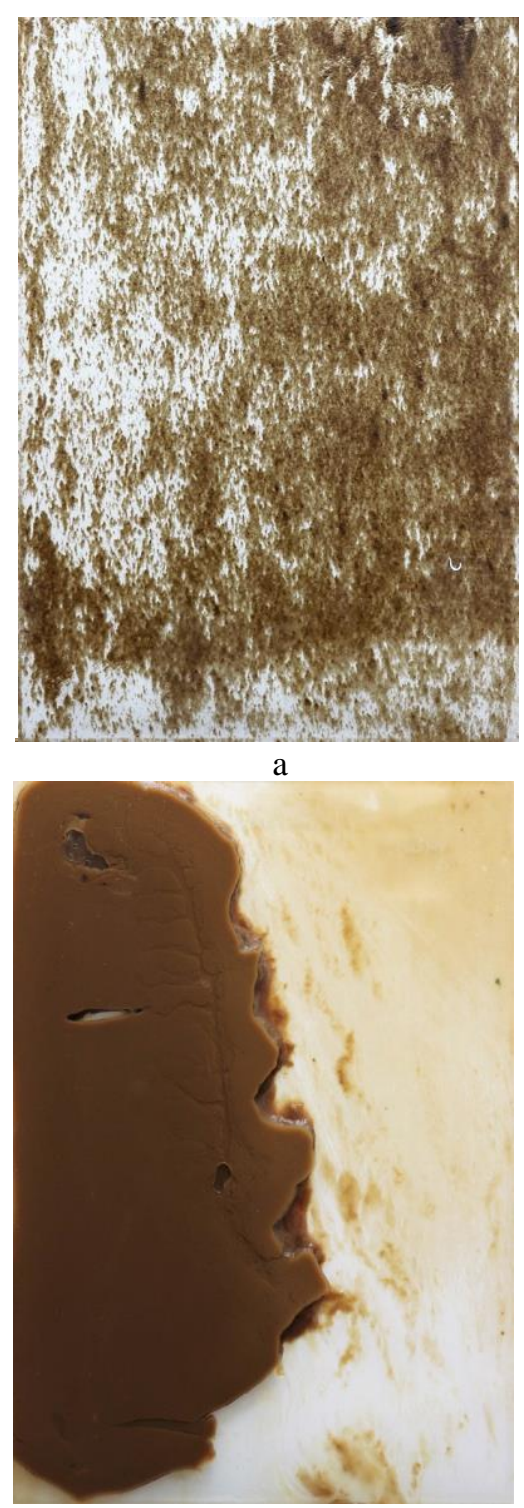

$\mathrm{b}$
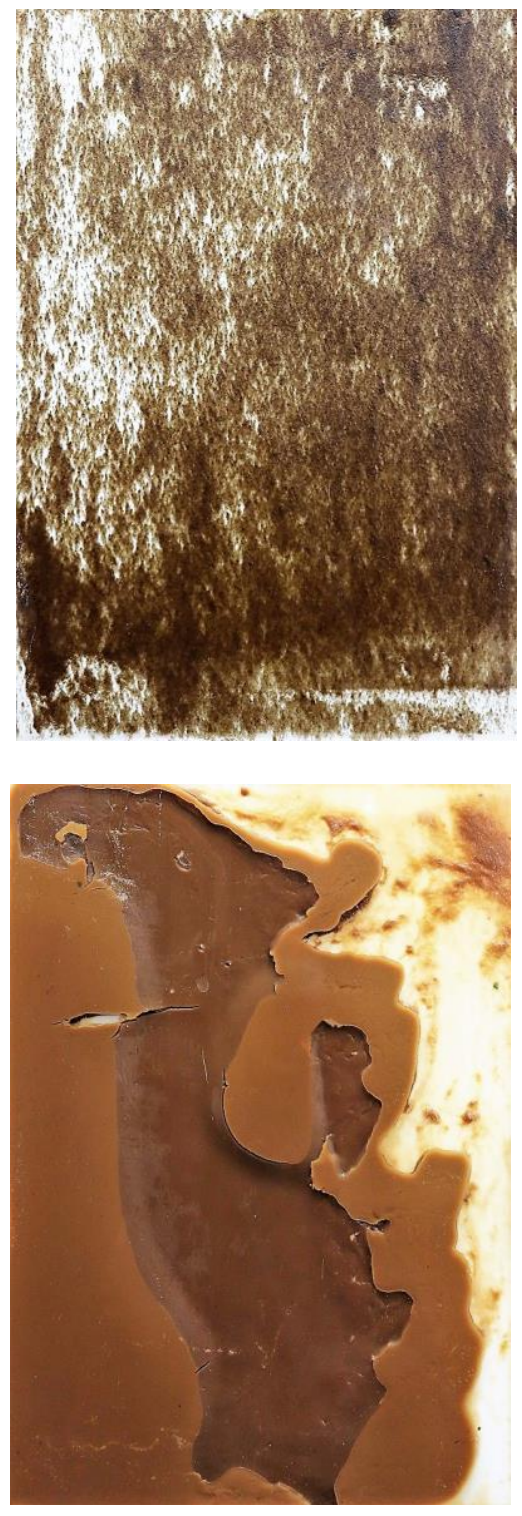

Figure 5: Examples of progressive sludging in 1-4 hour timeframe: (a) municipal, and (b) industrial MBR sludge sample, MLSS $=8-12 \mathrm{~g} \cdot \mathrm{L}^{-1}, U_{a}=0 \mathrm{~m} \cdot \mathrm{s}^{-1}$. 


\subsection{Permeability and sludging vs CST, SCOD \& rheology, 8-12 g. L $^{-1} \mathrm{MLSS}$}

Sludging only took place for $33 \%$ of the industrial sludge samples, whereas it was evident for all but one of the municipal sludges. Sludging associated with the industrial samples was of a more onerous nature, since it completely filled the channels (Fig. 5b), rather than forming a thick cake on the membrane surface (Fig. 5a). As such it more truly represents what is practically recognised as sludging.

Data for the permeability decline rates $\Delta K / \Delta t$ in $\mathrm{mLMH} \cdot \mathrm{bar}^{-1} \cdot \mathrm{h}^{-1}$ and sludging rates in percentage of surface area occluded for operation at fixed flux values are depicted in Fig. 6. The industrial data includes both the sludging and non-sludging data (the open and filled diamond markers respectively), i.e. permeability decline recorded both with and without visible sludging. These two data sets show no pattern and are indistinguishable: there is no apparent synergy between fouling and sludging, in that rapid permeability decline is not associated with commensurately rapid sludging. The instances of sludging were entirely vagarious under the conditions applied (i.e. 8-12 g. $\mathrm{L}^{-1}$ MLSS and zero aeration). Moreover, the sludging rate does not appear to be a function of flux under the conditions tested, which is counter-intuitive. However, the data reflect the higher fouling and sludging propensity of the industrial sludge, which fouls and sludges at lower flux values and at a faster rate, compared with the municipal sludge, albeit with highly scattered data.

The greater fouling and sludging propensity of the industrial sludge is more clearly demonstrated by considering data based on a single flux (Fig. 7). For a flux value of 20 LMH (19.6-20 LMH) for the averaged values from four individual sludge sample tests, it is apparent that all the key measured sludge quality parameters (CST, sCOD and $\mu_{\gamma=120}$ ) increase from the municipal to the industrial samples from between $76 \%$ for the sCOD to $390 \%$ for $\mu_{\gamma=120}$. The mean $\Delta K / \Delta t$ and $\% \mathrm{C}$ values accordingly increase by $105 \%$ and $76 \%$ respectively. Whilst this confirms the greater fouling and sludging propensity of the industrial sludge, there is no clear indication as to which property of the sludge accounts for sludging.

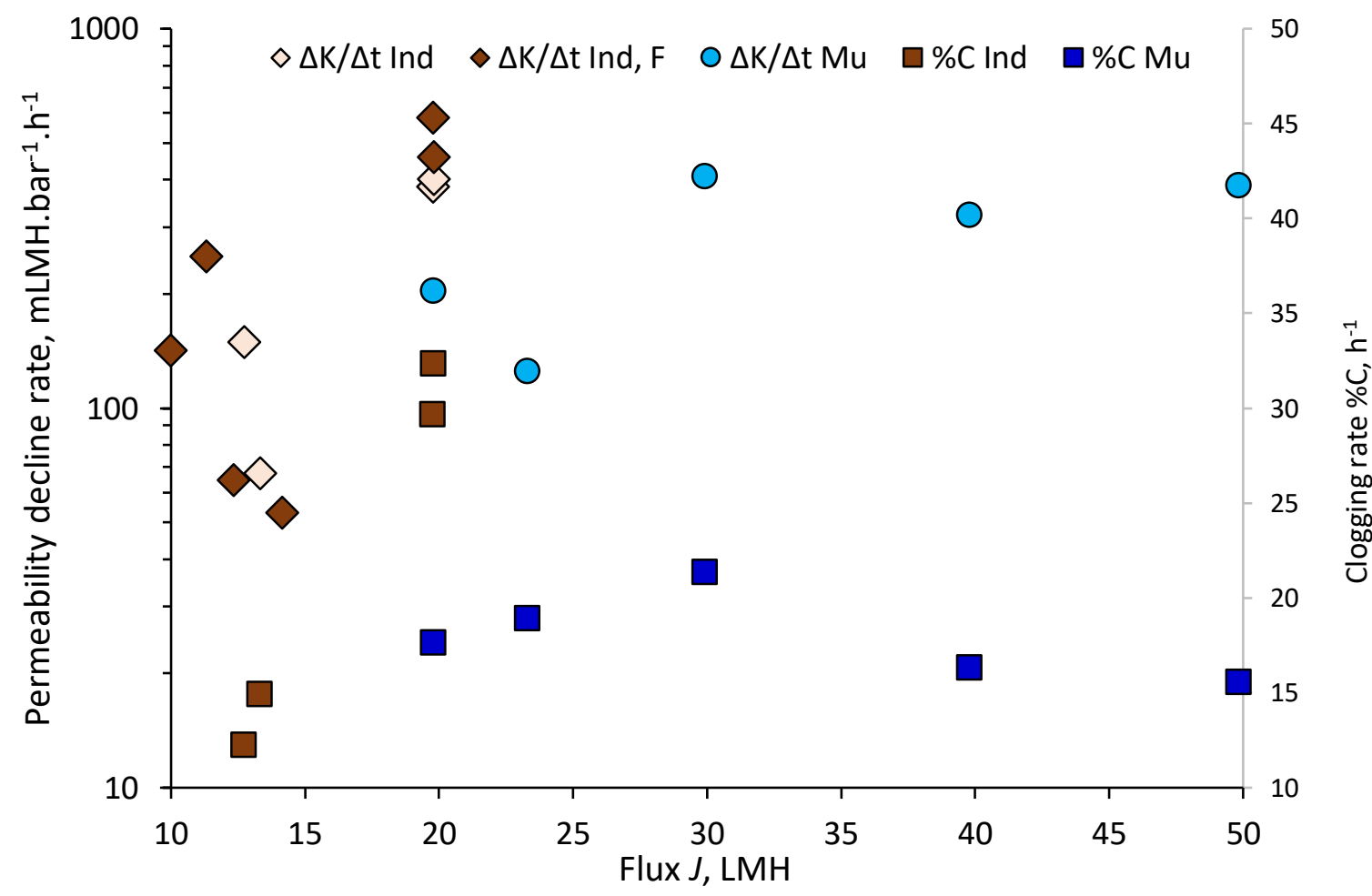

Figure 6: Permeability decline and sludging rates for municipal and industrial sludge samples,MLSS $=8-12$ g.L.-1, $U_{a}=0 \mathrm{~m} . \mathrm{s}^{-1}$. 


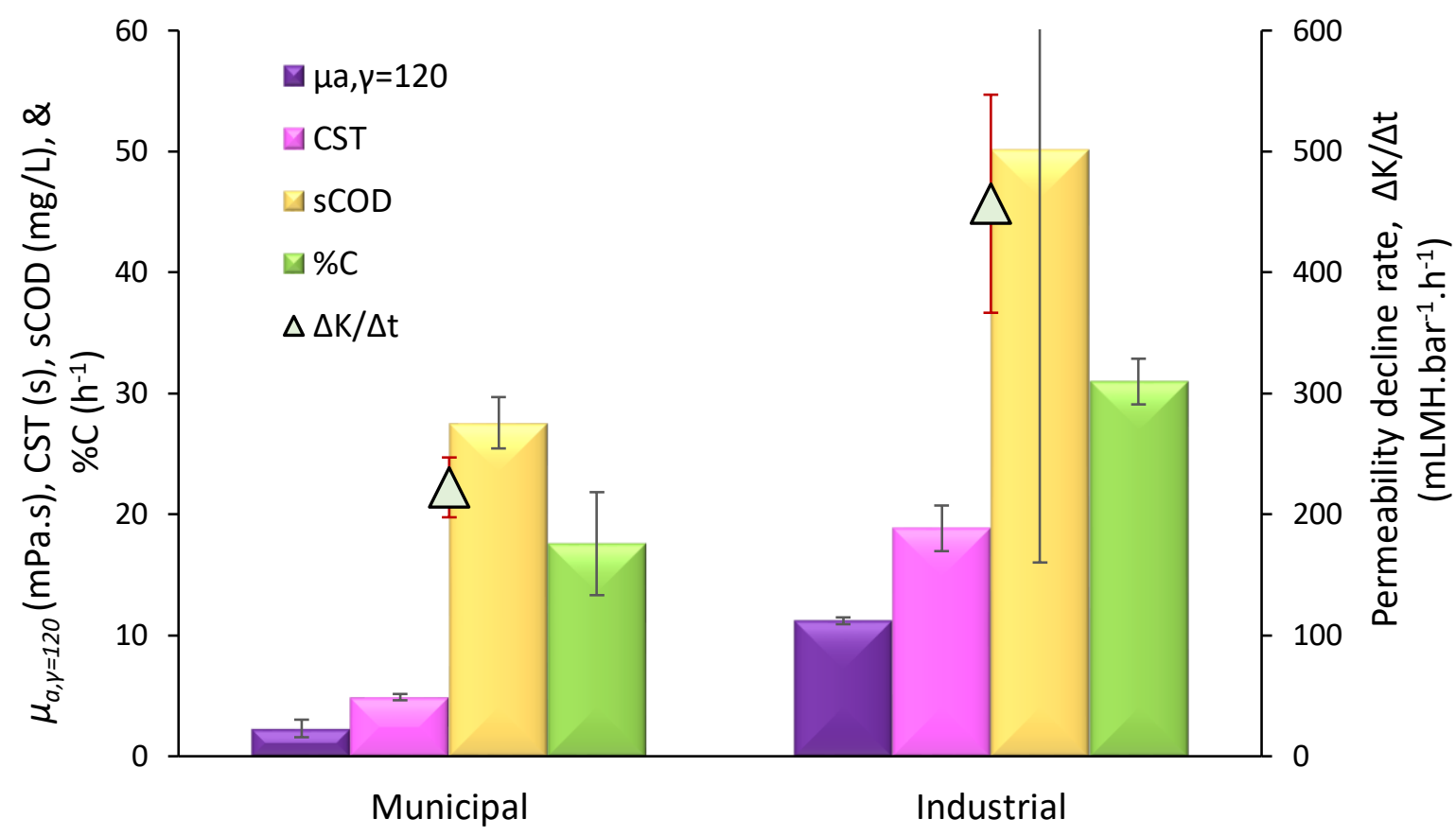

Figure 7: Mean parameter values for the municipal and industrial sludge samples, Campaign 2 (zero membrane aeration), 8-12 g. $\mathrm{L}^{-1}$ solids concentration.

\subsection{Studies at high MLSS}

For Campaign 3 tests were conducted at higher MLSS $(16-22 \mathrm{mg} / \mathrm{L})$ through concentrating the solids by membrane thickening. This produced the expected increase in MLSS concentration without significantly affecting the COD. Any change in fouling or sludging behaviour could thus be attributed to the physical sludge properties, i.e. dewaterability or rheology.

Results averaged across four samples for each sludge type (Fig. 8) indicated that, for the municipal sludge, sludging remained very low even at the higher solids levels under zero aeration conditions. The higher mean $n$ value, increasing from 0.15 to 0.25 from low to high solids concentration, is therefore associated purely with fouling phenomena possibly pertaining to the SCOD, which increased by about the same percentage ( $65 \%)$ whereas the CST increased by only $18 \%$.

In the case of the industrial sludge increasing the solids concentration resulted in a three-fold increase in the sludging rate (the light green hatched bar in Fig. 8) - from 30 to $90 \% \cdot \mathrm{h}^{-1}$ on average - under conditions of zero aeration. For this sample the SCOD actually decreased slightly from the low to high solids concentration, such that the sludging could not be linked to COD. The CST, on the other hand, also increased by about the same factor (from 19 to $54 \mathrm{~s}$ ). The $\mu_{s, y=120}$ value also approximately trebled in value, from 12 to $35 \mathrm{mPa}$.s, for the industrial sludge. However, in this instance the trend is likely to be purely coincidental, since sludge rheology is extremely complex (Eshtiaghi et al, 2013).

On repeating the test with vigorous aeration (at $0.055 \mathrm{~m} \cdot \mathrm{s}^{-1}$ ) sludging still took place (at around $20 \% \cdot \mathrm{h}^{-}$ ${ }^{1}$, Fig. 8, dark green dotted bar), despite a decrease in $n$, and affording the opportunity of direct observation of the aeration pattern for a sample undergoing sludging. This revealed (a) the air bubbles to coalesce to produce larger bubbles, and (b) the air bubble stream to constrict, such that the sides of the membrane channel received less scouring air. Inspection of the sludged membrane channel revealed these areas to be subject to sludging (Fig. 9). 


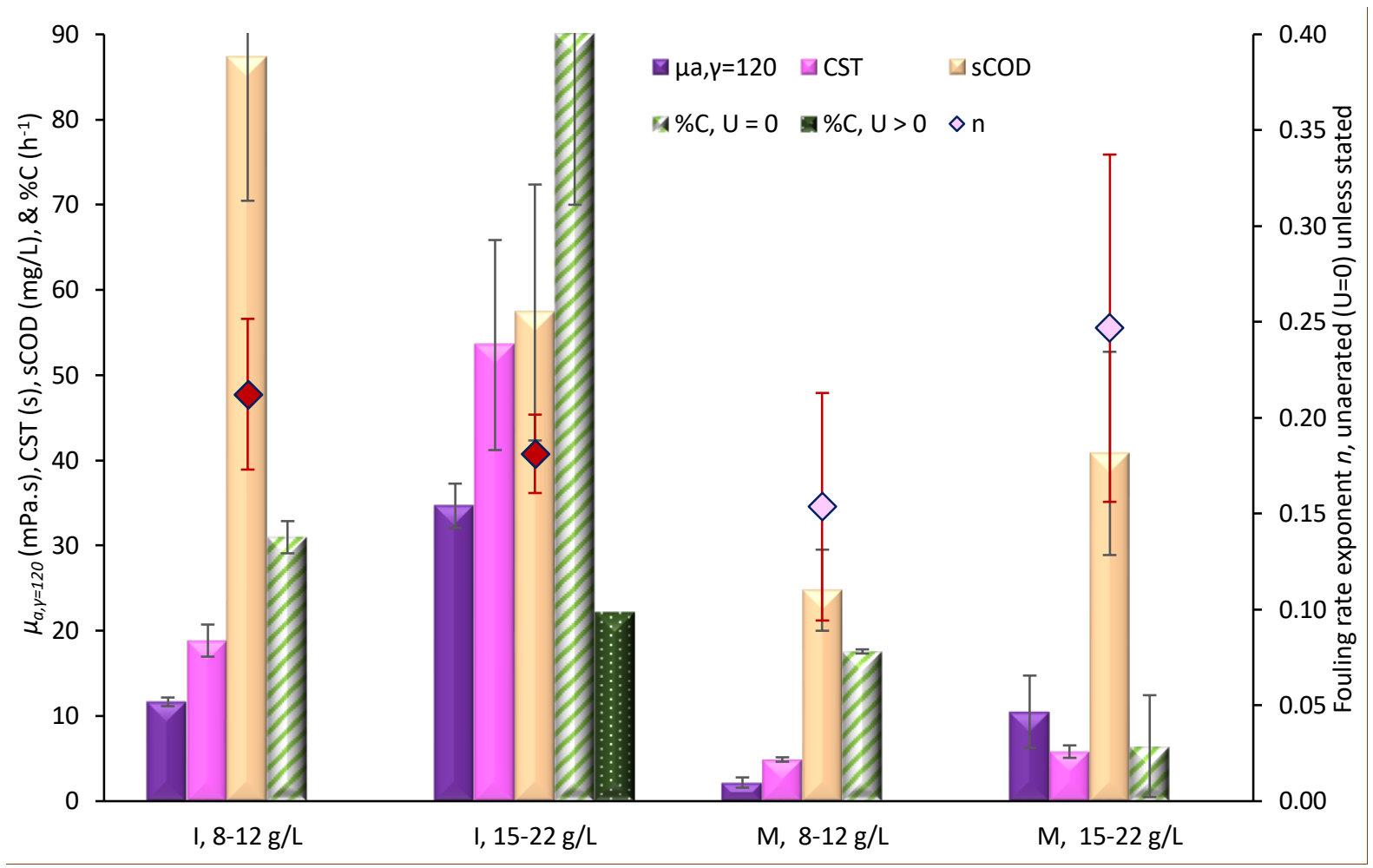

Figure 8: $\quad$ Mean industrial and municipal sludge fouling and sludging determinants (from a sample of 4). $n$ relates to the unaerated condition, other than for the industrial sludge sample (red diamond). \%C data for both the aerated (dark green) and unaerated (light green) is shown.
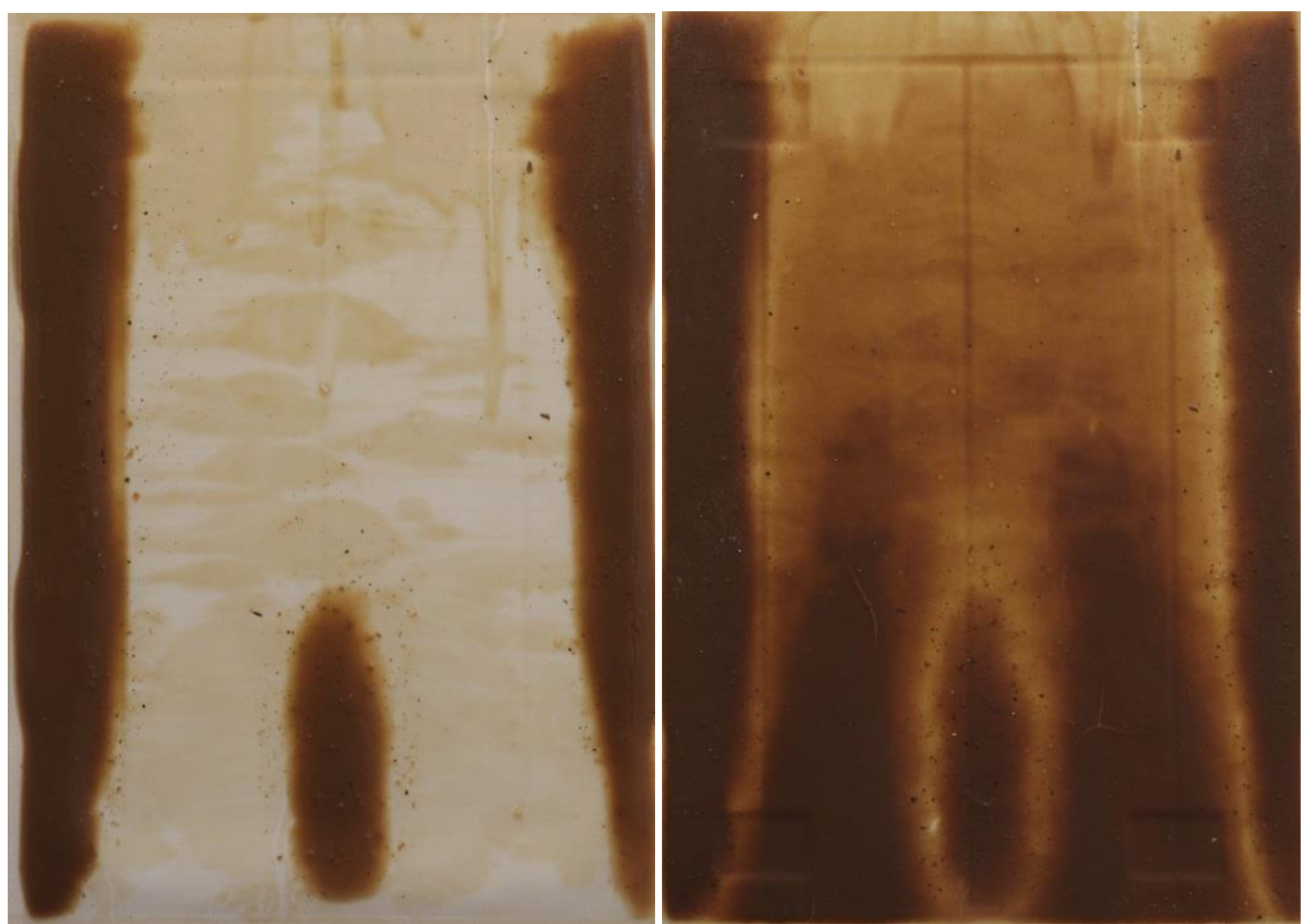

Figure 9: $\quad$ Sludged solids pattern for aerated industrial sludge sample at MLSS concentration of 18-22 g.L $\mathrm{L}^{-1}$ 
The impact of viscosity on aeration has been previously reported for fine bubble aerators with reference to both the constriction of the air bubble stream (Fabiyi and Novak, 2008) and bubble coalescence (Amaral et al, 2018) at increased viscosities. However, there appears to have been no previous reports of impacts on coarse bubble aerators and the consequences regarding non-uniform air-scouring of membranes.

Finally, this result reveals that sludging is not detectable from the observed pressure decline rate. Sludging of the channel for the industrial sludge did not significantly influence the fouling exponent value $n$ (the red diamond markers in Fig. 8). Thus incipient sludging does not necessarily impact on membrane hydraulic performance over the limited duration of the tests. However, extensive consolidation of the solids filling the membrane channel to produce a sparingly-permeable cake, effectively occluding the membrane surface, is ultimately profoundly detrimental to the MBR process.

\section{Conclusions}

A study of the clogging (or sludging) of a flat sheet (FS) membrane channel in an immersed membrane bioreactor (iMBR) has been carried out. Mixed liquor (or sludge) samples were extracted from both a municipal and industrial full-scale MBR installation, and a bespoke test cell used to quantify fouling and sludging propensity. Sludging was quantified through visually determining the occlusion of the membrane surface by the attached solids.

The work has demonstrated:

1. The measured fouling propensity $n$, as given by the pressure incline rate equation $\Delta p / \Delta t=m$. $\exp (n J)$ equation and determined from flux-step experiments, was comparable with those reported for other studies conducted on municipal wastewater MBR sludge.

2. Whereas the industrial sludge samples exhibited sludging, i.e. the filling of the complete membrane channel thickness with sludge solids, the municipal sludge solids formed a cake of finite thickness on the membrane surface.

3. The industrial sludge also exhibited higher permeability decline rates, higher soluble COD (sCOD) concentrations, higher CST and higher viscosities than the municipal sludge at the same MLSS concentration range (8-12 g. $\left.\mathrm{L}^{-1}\right)$.

4. No correlation between fouling (permeability decline in the absence of sludging) and sludging was evident: incipient sludging does not appear to influence permeability, or relate to the sCOD concentration.

5. Evidence suggests that sludging is linked to physical properties of the sludge, and primarily the viscosity. Sludge samples at high solids concentrations and correspondingly high viscosities were found to exhibit a different aeration pattern to that observed at normal MLSS concentrations

The work suggests that sludging arises when the rheological conditions promote bubble coalescence and bubble stream constriction, reducing the exposure of the membrane surface to scouring air. However, the susceptibility of sludge to sludging, even the absence of scouring air, varies significantly for sludges of differing physical properties, as evidenced by the different sludging propensities of the municipal and industrial samples at the same MLSS concentration. Further work is needed to establish whether previously reported changes in rheological behaviour with measurable bulk sludge physical properties (floc size, solids concentration, CST, etc) can semi-quantitatively account for sludging.

\section{$5 \quad$ Acknowledgements}

This work was made possible by the support of a National Priorities Research Programme (NPRP) grant from the Qatar National Research Fund (QNRF), grant reference number NPRP8-1115-2-473. The statements made herein are solely the responsibility of the authors. The authors would like to thank Ashgal, Suez and Qatar Gas for their unstinting support of this work, Kubota Membranes Europe for supplying the membranes, and Yousef Elhamarnah for his assistance with the sampling. 


\section{References}

Amaral, A., Bellandi, G., Rehman, U., Neves, R., Amerlinck, Y., \& Nopens, I. (2018). Towards improved accuracy in modeling aeration efficiency through understanding bubble size distribution dynamics. Water Res., in press.

American Public Health Association (APHA). American Water Works Association (AWWA) and Water Environment Federation (WEF): Standard Methods for the Examination of Water and Wastewater, 22nd Edition (2012).

Aslam, M., Charfi, A., Lesage, G., Heran, M., Kim, J. (2017). Membrane bioreactors for wastewater treatment: A review of mechanical cleaning by scouring agents to control membrane fouling. Chem. Eng. J., 307, 897-913.

Böhm, L., and Kraume, M. (2015). Fluid dynamics of bubble swarms rising in newtonian and non-newtonian liquids in flat sheet membrane systems. J. Membr. Sci., 475, 533-544.

Buzatu, P., Zsirai, T., Aerts, P., Judd, S.J. (2012). Permeability and clogging in an immersed hollow fibre membrane bioreactor. J. Membr. Sci., 421-422, 342-348.

Cui, Z.F., Chang, S. and Fane, A.G. (2003). The use of gas bubbling to enhance membrane processes. J. Membr. Sci., 221, 1-35.

Diez, V., Ezquerra, D., Cabezas, J. L., García, A., and Ramos, C. (2014). A modified method for evaluation of critical flux, fouling rate and in situ determination of resistance and compressibility in MBR under different fouling conditions. J. Membr. Sci., 453, 1-11.

Drews, A. (2010). Membrane fouling in membrane bioreactors-characterisation, contradictions, cause and cures. J. Membr. Sci., 363(1-2), 1-28.

Eshtiaghi, N., Markis, F., Yap, S. D., Baudez, J-C., and Slatter, P. (2013). Rheological characterisation of municipal sludge: A review. Water Res., 47(15), 5493-5510.

Fabiyi, M., and Novak, R. (2008). Evaluation of the factors that impact successful MBR operatinos at high solids concentration, Proceedings of the Water Environment Federation, Membrane Technology 2008, 503-512(10).

Frechen, F. B., Schier, W. and Linden, C. (2008). Pre-treatment of municipal MBR applications. Desalination, 231(1-3), 108-114.

Fulton, B. G., Redwood, J., Tourais, M., \& Bérubé, P. R. (2011). Distribution of surface shear forces and bubble characteristics in full-scale gas sparged submerged hollow fiber membrane modules. Desalination, 281(1), 128141.

Gabarrón, S., Gómez, M., Monclús, H., Rodríguez-Roda, I., Comas, J. (2013). Ragging phenomenon characterisation and impact in a full-scale MBR. Wat. Sci. Technol., 67(4), 810-816.

Gabarrón, S., Gómez, M., Dvořák, L., Růžičková, I., Rodriguez-Roda, I., Comas, J. (2014). Ragging in MBR: Effects of operational conditions, chemical cleaning, and pre-treatment improvements, Sep. Sci. Technol., 49 (14), 2115-2123.

Impero, J. (2015). MBR Screening Part 1: MBR screen designs and performance - an overview. The MBR Site, http://www.thembrsite.com/features/mbr-screening-part-1-mbr-screen-designs-and-performance-an-overview/, accessed March 2018.

Judd, S. (2014). Industrial MBRs, Judd \& Judd, Cranfield.

Krzeminski, P., Leverette, L., Malamis, S., Katsou, E. (2017). Membrane bioreactors - A review on recent developments in energy reduction, fouling control, novel configurations, LCA and market prospects. J. Membr. Sci., 527, 207-227.

Le-Clech, P., Jefferson, B., Chang, I.S., Judd, S.J. (2003). Critical flux analysis by the flux step method in a submerged membrane bioreactor", J. Membr. Sci. 227(1-2) 81-93.

Le-Clech, P., Chen, V., Fane, T.A.G. (2006). Fouling in membrane bioreactors used in wastewater treatment. J. Membr. Sci., 284 (1-2), 17-53.

Lin, H., Zhang, M., Wang, F., Meng, F., Liao, B., Hong, H., Gao, W (2014). A critical review of extracellular polymeric substances (EPSs) in membrane bioreactors: Characteristics, roles in membrane fouling and control strategies. J. Membr. Sci., 460, 110-125. 
Mason, S., Ewert, J., Ratsey, H., Sears, K. and Beale, J. (2010). Flat sheet membrane bioreactors operational experiences - a New Zealand perspective. Proceeding in NZWWA Conference, Christchurch, Canterbury, New Zealand.

Meng, F., Chae, S., Drews, A., Kraume, M., Shin, H., Yang, F. (2009). Recent advances in membrane bioreactors (MBRs): Membrane fouling and membrane material. Water Res., 43(6), 1489-1512.

Meng, F., Zhang, S., Oh, Y., Zhou, Z., Shin, H.-S., Chae, S.-R. (2017). Fouling in membrane bioreactors: An updated review, Water Res., 114, 151-180.

Monclus, H., Zacharias, S., Santos, A., Pidou, M., Judd, S. (2010). Criticality of flux and aeration for a hollow fiber membrane bioreactor. Sep. Sci. Technol., 45 (7), 956-961.

Ranieri, E., Goffredo, V., Campanella, M., and Falk, M. W. (2016). Flux-step method for the assessment of operational conditions in a submerged membrane bioreactor. Wat. Sci. Technol., 73(9), 2222-2230.

Reid, E., Liu, X., and Judd, S.J. (2008). Sludge characteristics and membrane fouling in full-scale submerged membrane bioreactors, Desalination, 219(1-3), 240-249.

Stefanski, M., Kennedy, S. and Judd, S. (2011). The determination and origin of fibre clogging in membrane bioreactors. J. Membr. Sci., 375(1-2): 198-203.

Stone, M. and Livingston, D (2008) Flat plate MBR energy consumption - village of Dundee, MI. Membrane Technology Conference Proceedings of the Water Environment Federation, Alexandria (VA) Jan 27-30.

Ranieri, E., Goffredo, V., Campanella, M., and Falk, M. W. (2016). Flux-step method for the assessment of operational conditions in a submerged membrane bioreactor. Wat. Sci. Technol., 73(9), 2222-2230.

The MBR Site (2015) The 2015 MBR Survey results, http://www.thembrsite.com/features/2015-mbr-surveyresults/, accessed July 2017

Wang, Z., Ma, J., Tang, C.Y., Kimura, K., Wang, Q., Han, X. (2014) Membrane cleaning in membrane bioreactors: A review. J. Membr. Sci., 468, 276-307.

Verrecht, B., Judd, S., Guglielmi, G., Mulder, J.W., and Brepols, C. (2008) An aeration energy model for an immersed membrane bioreactor, Water Res., 42 4761-4770

Yang, M., Yu, D., Liu, M., Zheng, L., Zheng, X., Wei, Y., Wang, F, and Fan, Y. (2017). Optimization of MBR hydrodynamics for cake layer fouling control through CFD simulation and RSM design. Biores. Technol. 227 102-111.

Zsirai, T., Wang, Z.-Z., Gabarrón, S., Connery, K., Fabiyi, M., Larrea, A., Judd, S.J. (2014) Biological treatment and thickening with a hollow fibre membrane bioreactor Water Res., 58, 29-37. 